\title{
O processo de acumulação na Economia Política Clássica: uma interpretação não convencional a partir da leitura dos ricos detalhes comumente inexplorados
}

\author{
André Luís Cabral de Lourenço* \\ Luziene Dantas de Macedo* \\ Márcia Maria de Oliveira Bezerra*** \\ Marconi Gomes da Silva**** \\ William Eufrásio Nunes Pereira ${ }^{* * * * *}$
}

Resumo: O artigo visa tratar o processo de acumulação na economia clássica à luz da geopolítica do desenvolvimento. Sua hipótese é que uma leitura detalhada dos clássicos permite repor, sobretudo em seus aspectos normativos, algum nível de politização não considerada na sua parte convencionalmente mais difundida. Para tanto, três confrontos são centrais nas relações entre: i) Estado, comércio exterior e desenvolvimento; ii) lei de Say versus princípio da demanda efetiva; iii) crescimento econômico, distribuição de renda e a natureza como possível limite à acumulação. Busca-se em cada item captar detalhes que propiciam alguma (re)politização da discussão no debate contemporâneo.

Palavras-Chave: Acumulação e crescimento. Economia política clássica. Geopolítica do desenvolvimento. Politização. Distribuição de renda.

\section{Accumulation process in Classical Political Economy: an unconventional interpretation based on the reading of rich detail usually unexplored}

\begin{abstract}
The article aims to address the accumulation process in classical economics in the light of geopolitical development. His hypothesis is that a close reading of the classics allows to reset, especially in its normative aspects, some level of politicization not conventionally considered in its more widespread part. Therefore, three clashes are central in relations between: i) State, foreign trade and development; ii) Say's law versus principle of effective demand; iii) economic growth, income distribution and nature as possible limit to accumulation. Each item tries to capture details that provide some (re) politicization of the discussion in the contemporary debate.
\end{abstract}

Keywords: Accumulation and growth. Classical political economy. Development geopolitics. Politicization. Income distribution.

Classificação JEL: F50; B12; N50.

\footnotetext{
*Doutor em Economia pelo IE/UFRJ e professor associado do Departamento de Economia da UFRN. E-mail: andre-lourenco@uol.com.br.

** Doutora em Desenvolvimento Econômico pelo Instituto de Economia da Unicamp - Área: Desenvolvimento Econômico, Espaço e Meio Ambiente. Professora Adjunto do Departamento de Economia da Universidade Federal do Rio Grande do Norte. E-mail: luzienedm@uol.com.br.

**** Doutora em Economia pelo IE/Unicamp e professora associada do Departamento de Economia da UFRN. Email: marciabezerra@ufrnet.br.

***** Doutor em Desenvolvimento Regional/Ciências Sociais (UFRN). Professor do Departamento de Economia (UFRN). E-mail: marconi.br62@gmail.com.

****** Doutor em Ciências Sociais pela UFRN. Professor adjunto do Departamento de Economia e Coordenador do Programa de Mestrado em Economia da Universidade Federal do Rio Grande do Norte. E-mail: willa@ufrnet.br.
} 


\section{Introdução}

O presente artigo toma como ponto de partida a crítica feita por Fiori (1999), segundo a qual a economia política clássica empreendeu um processo de despolitização da ciência econômica ao tentar explicar a dinâmica da economia através do livre mercado e, portanto, desconsiderando o sujeito político por excelência da economia: o Estado. Segundo Fiori (1999, p. 49):

Ao defender a tese de que uma mudança na correlação de forças entre os Estados era uma condição indispensável a uma maior equidade entre as nações, Adam Smith propôs à economia política clássica uma questão e um caminho que ele mesmo, posteriormente, abortou.

Partindo da ideia de que a crítica de Fiori está correta quanto ao centro da teorização da economia política clássica, tem-se como principal objetivo no presente artigo o empreendimento de uma leitura anticonvencional do processo de acumulação na economia política clássica, investigando os detalhes econômicos à luz da geopolítica do desenvolvimento. Com vistas a atingir o objetivo proposto, parte-se da hipótese de que uma leitura em detalhe dos clássicos permite constatar que em pontos específicos das obras desses autores, principalmente naquelas em que são enfocados aspectos normativos, é reposto algum nível da politização ausente na "parte dura" da elaboração teórica, indicando que a visão liberal pasteurizada dos autores clássicos, nas versões de manual, constituiu-se componente adicional da despolitização presente na parte dura da teoria clássica.

Este artigo consiste em parte de uma agenda de pesquisa mais ampla, que procura investigar as concepções de desenvolvimento presentes na teoria econômica. Por isso, iniciase a pesquisa teórica com a investigação do processo de acumulação na economia política clássica. Para alcançar tal objetivo, a investigação está estruturada, tendo como ponto de partida uma revisão bibliográfica sobre a temática da acumulação em Smith, Ricardo e Malthus utilizando-se como chave interpretativa a geopolítica do desenvolvimento e a teoria econômica heterodoxa contemporânea.

O trabalho está dividido em três partes, além dessa introdução e das considerações finais. A primeira parte procura apresentar a visão dos mercantilistas sobre o comércio exterior e o Estado, bem como sua importância para o desenvolvimento da economia nacional, buscando confrontá-la com a contribuição da economia política clássica sobre o livre comércio. Na segunda parte do artigo são apresentados a lei de Say e o princípio da demanda efetiva como princípios estruturantes da concepção clássica da acumulação do capital. Com base na lei de Say, a acumulação é regida pela produção (oferta) como aparece 
nas obras de Smith e Ricardo. Por outro lado, se adota o princípio da demanda efetiva, como é o caso de Malthus, é a demanda que tem papel ativo para o processo de acumulação. Também são tecidas considerações sobre as implicações dos citados princípios para a dinâmica da população e do mercado de trabalho. A terceira parte do estudo enfoca peculiaridades inerentes à contribuição teórica de Smith, Ricardo e Malthus, observando as implicações que as respectivas contribuições têm para a explicação do crescimento econômico e da distribuição de renda na sociedade capitalista. Um elemento comum de estudo nesses autores, em particular em Ricardo, consiste na visão da natureza como limite ao processo de acumulação de riqueza, dada a sua finitude. Por fim, são apresentadas as considerações finais. Nessa parte do artigo será realizada a síntese das conclusões parciais apresentadas no corpo do trabalho para ressaltar o grau de confiança na hipótese norteadora da pesquisa e, além disso, para indicar os desdobramentos da pesquisa.

\section{Mercantilismo x livre comércio}

A recuperação de aspectos nucleares à doutrina mercantilista e a visão que economistas clássicos têm acerca dos mesmos, explicitada nas obras de Smith (1776), Ricardo (1817) e Malthus (1820) é essencial para entender o papel que tais autores atribuem ao comércio internacional no processo de acumulação de capital, e as defesas que fazem de políticas no seu campo normativo.

Esta seção pretende examinar as idéias que sustentaram as posições mercantilistas em favor do protecionismo e as críticas efetuadas por Smith e Ricardo a tais políticas de intervenção, fundadas tanto na consideração de sua ineficácia, quanto nos benefícios que o livre comércio poderia proporcionar para o desenvolvimento das economias participantes.

$\mathrm{Na}$ doutrina mercantilista, o acúmulo de metais preciosos era indispensável para o fortalecimento dos Estados Nacionais em meio às ameaças representadas por Estados rivais. Em tal contexto, o comércio exterior era o mecanismo através do qual o país teria acesso às espécies preciosas, capazes de fortalecer o poder do 'Príncipe' à medida que favorecesse a acumulação interna de capital ${ }^{1}$. A percepção acerca dos efeitos benéficos gerados pelo saldo superavitário da balança comercial em termos de poder e riqueza orientou a ação política do Estado.

\footnotetext{
1 As ideias mercantilistas emergem em meio às transformações econômicas suscitadas pelo declínio do feudalismo e o aparecimento das monarquias absolutistas. Assim, tornava-se claro para os seus defensores que o crescimento da economia conduziria ao incremento das receitas tributárias com as quais seria possível sustentar grandes exércitos. Na visão de Deyon $(1969$, p. 52), as práticas mercantilistas no mais das vezes traduziam a "ambição de dominar as potências estrangeiras".
} 
As práticas mercantilistas resultantes estavam fundadas na consideração dos mecanismos pelos quais o saldo da balança comercial superavitário operava, quais sejam: i) o comércio internacional contribuiria para a expansão da agricultura e manufatura à medida que gerasse demanda externa para o excedente produzido internamente, favorecendo o processo de acumulação de capital; e ii) a sustentação do superávit comercial permitiria que o país adotasse uma política monetária compatível com o crescimento da economia doméstica, mediante a manutenção de taxas de juros relativamente baixas.

Neste sentido, os mercantilistas dirigiam suas preocupações para as seguintes variáveis de política econômica: i) saldo do balanço de pagamento; ii) e taxa de juros interna ${ }^{2}$. Em uma época em que o acesso aos recursos externos dependia basicamente do saldo da balança comercial, dado o relativamente baixo fluxo de capitais, os mercantilistas reconheciam que para atingir seus objetivos de riqueza e prosperidade precisavam formular políticas comerciais consistentes, nas quais deveria constar a adoção de programas aduaneiros. Os mesmos tinham em vista favorecer as exportações de produtos manufaturados e proibir as importações de produtos concorrentes, assim como a defesa do manejo de tarifas, representando aspectos típicos de emprego de políticas protecionistas ${ }^{3}$.

$\mathrm{O}$ acesso ao estoque de metais preciosos que as exportações líquidas proporcionariam, por sua vez, permitiria firmar a "base de um sistema de crédito rudimentar" (DEYON, 1969, p. 57). Desse modo, a acumulação desses recursos seria o mecanismo por meio do qual poderia ser assegurada a queda das taxas de juros internas, o que para Keynes (1936) era de suma importância, uma vez que "as autoridades não tinham controle sobre as taxas de juros internas nem sobre os outros estímulos para o investimento nacional” (KEYNES, 1936, p. 259).

Neste sentido, este segundo mecanismo, que revela a conexão que os mercantilistas estabeleciam entre política comercial e política monetária, também contribuiria indiretamente para gerar demanda na economia. Afinal, taxas de juros baixas tendiam a estimular o aumento da demanda por investimentos no país, elevando a sua capacidade de produzir riqueza e competir com os outros Estados-Nações. Contudo, para que as taxas de juros pudessem estimular as inversões não poderia haver pleno entesouramento dos recursos obtidos com as exportações líquidas, ou seja, o dinheiro deveria circular. Um nível de entesouramento alto,

\footnotetext{
${ }^{2}$ KEYNES, J. M. The General Theory of Employment, Interest and Money (1936, p. 259).

${ }^{3}$ Deyon (1969, p. 54) chama atenção para outros aspectos importantes das políticas comerciais defendidas pelos mercantilistas, tais como o estímulo às companhias de navegação, mediante a concessão de monopólios, e em uma perspectiva bem ampla as "novas colônias", que constituem uma das armas "utilizadas nessa guerra da prata".
} 
que implicasse na retenção por parte dos agentes dos estoques de metais preciosos acumulados no país, reduziria o efeito de baixa que esse acúmulo teria sobre as taxas de juros, ainda que vigorasse a lei da usura.

O acúmulo de reservas em metais preciosos proporcionado pela consolidação das políticas protecionistas permitiria manter a taxa de câmbio nominal estável. Este fator aliado a expansão da oferta gerada pela ampliação da capacidade produtiva da economia, proporcionada pelos investimentos, evitaria a ocorrência de pressões inflacionárias no contexto de aumento da demanda.

Neste sentido, o crescimento econômico gerado pelas demandas externa (saldo superavitário da balança comercial) e interna (aumento do investimento induzido pela queda das taxas de juros, com efeito positivo sobre expansão da oferta), seria real - incorporando terras e empregando pessoas ao desenvolver a agricultura, o comércio e a manufatura, e não apenas produto do crescimento dos preços. Em suma, em linguagem contemporânea os mercantilistas viam o crescimento econômico como um processo liderado pela demanda e restringido pelo balanço de pagamento.

As ideias mercantilistas estruturadas em torno da balança comercial sofreram fortes críticas a partir de Hume (1752) com sua hipótese do preço-fluxo de metais preciosos, fundada na teoria quantitativa da moeda (GONÇALVES et al., 1998; DEYON, 1969). Nesta perspectiva, as políticas protecionistas seriam ineficazes para ampliar de forma permanente o superávit comercial de um país, pois um aumento no estoque de metais preciosos que as mesmas desencadeassem teria efeito sobre os preços domésticos e não sobre produção e emprego (dado o suposto de oferta inelástica decorrente da utilização da lei de Say), elevando-os (supondo ausência de esterilização).

A valorização real do câmbio, que se seguiria ao movimento ascendente dos preços internos no contexto de uma taxa de câmbio nominal fixa, reduziria a competitividade dos produtos nacionais frente a outros concorrentes nos mercados doméstico e externo, acarretando a queda das exportações e o aumento das importações (supondo que a condição de Marshall-Lerner seja obedecida e o país seja pequeno). O superávit diminuiria e o mecanismo em questão continuaria operando até eliminá-lo completamente. Estancada a entrada de ouro, as reservas e a base monetária se estabilizariam, assim como os preços e a taxa de câmbio real. Ao final do processo, o único efeito permanente da política protecionista seria o de promover uma valorização real da taxa de câmbio, compensando completamente o efeito inicial dessa política sobre a produção e o emprego do país. 
Smith e Ricardo, defensores do livre comércio em geral, encontraram na visão do ajuste automático do balanço de pagamentos proposto por Hume a base para invalidar as teses mercantilistas que justificavam a adoção de políticas protecionistas. Em uma perspectiva mais ampla, Smith (1776, p. 91) tencionava mostrar que "um comércio que é forçado por subsídios e monopólios pode e costuma ser desvantajoso para o país que espera estar se beneficiando com essas medidas". Logo, ele esclarece, assim, que o que considera vantagem ou ganho diz respeito a renda anual dos habitantes de um país.

Ao analisar o comércio entre países, Smith utiliza o mesmo raciocínio que emprega para defender a expansão das trocas entre a cidade e o campo em um dado território, qual seja, a ocorrência de ganho simultâneo para os participantes proporcionado pela especialização. No caso das trocas no interior de um dado país, a cidade proporcionaria mercado para o excedente gerado no campo e os habitantes do campo poderiam adquirir da cidade maiores quantidades de produtos manufaturados a preços mais baixos. Mas, para estender seu argumento baseado na consideração das vantagens absolutas no caso do comércio externo, o referido autor necessita recorrer à incorporação do mecanismo de ajuste automático do balanço de pagamentos supracitado de Hume em seu sistema analítico, já que as transações ocorrem em moedas diferentes.

O modelo de Smith permite constatar que na ausência de qualquer interferência governamental que vise implantar medidas protecionistas à produção interna, a tendência é que as economias se especializem na exportação de mercadorias nas quais apresentem vantagens absolutas. O incremento de produtividade, assegurado pelo aumento da divisão do trabalho, resultaria na expansão da oferta das mercadorias que poderiam ser vendidas no comércio internacional a preços mais baixos. Desse modo, com o volume de receitas de exportações gerado o país poderia pagar por importações mais baratas, no contexto de operação do mecanismo de ajuste automático do balanço de pagamento que tende a promover o equilíbrio no balanço de pagamentos.

Ricardo (1817), igualmente defensor dos benefícios do livre comércio, levou o raciocínio de Smith às últimas conseqüências, mostrando que mesmo que um país não dispusesse de vantagens absolutas na produção de qualquer mercadoria, o mecanismo de Hume garantiria o surgimento de ao menos um produto com vantagens absolutas. Isto seria possível em decorrência da operação do mecanismo de ajuste automático do saldo da balança comercial, que reagiria ao déficit resultante de forma a provocar uma queda de reservas, redução da base monetária e dos preços. Haveria então desvalorização da taxa real de câmbio 
e ganho de competitividade até que surgisse ao menos um produto no qual o país apresentasse vantagem absoluta e que pudesse ser exportado até equilibrar a balança comercial. Tal movimento tenderia então a estancar a queda de reservas, equilibrando o fluxo de entrada e saída de ouro. Assim, dada a taxa de câmbio nominal fixa, a modificação na estrutura de preços relativos garantiria o melhor resultado para todos os países participantes do comércio internacional. O funcionamento desse mecanismo, como visto, depende de várias hipóteses que Ricardo também incorporou.

Desse modo, o autor supracitado conclui que o país se torna competitivo exatamente naquele produto no qual possui vantagem comparativa, ou seja, o que apresenta o custo de produção (medido em quantidade de trabalho) mais baixo comparativamente ao das outras mercadorias que são produzidas internamente. Ao incorporar o mecanismo de Hume, combinado com a consideração das vantagens comparativas, Ricardo vai mais longe e determina o padrão de comércio dos países, mostrando que eles irão se especializar naqueles produtos nos quais internamente dispõem de vantagens comparativas. E isto ocorrerá ainda que inicialmente apresentassem desvantagens na produção de tais produtos (custos de produção mais elevados) quando comparados a outros países.

O sistema analítico desse pensador permite assim definir a pauta de exportação e de importação de um país e concluir que qualquer tipo de intervenção estatal para estimular a produção nacional e modificar essa situação será ineficaz. A exposição resumida das ideias que sustentam as posições dos mercantilistas e dos economistas clássicos defensores do livre comércio permite o tratamento, ainda que em caráter bastante preliminar, de aspectos fundamentais ao entendimento de algumas questões que continuam a ser contemporâneas. Assim, inicialmente, convém considerar as hipóteses que fundamentam as abordagens mercantilistas, com a qual Malthus (1820) parece se afinar, e as de Smith e Ricardo.

No caso dos mercantilistas, as exportações podem ser vistas como um fator gerador de demanda interna e o saldo da balança comercial como elemento de ruptura das restrições de balanço de pagamento ao crescimento econômico. Esta percepção está fundada no que posteriormente veio a ser conhecido como princípio da demanda efetiva. Não por acaso Keynes (1936), no cap. XXIII, mostra que as idéias mercantilistas eram defensáveis. Ademais, os adeptos das idéias mercantilistas não parecem concordar com a validade do mecanismo de ajuste automático do saldo do balanço de pagamento, que supõe para funcionar 
a validade do que posteriormente veio a ser conhecida como condição de Marshall-Lerner ${ }^{4}$, bem como de diversas outras hipóteses.

Para melhor compreensão dessa questão, é necessário examinar as suposições sobre as quais Hume (1752) desenvolve o seu modelo, incluindo a teoria quantitativa da moeda (TQM). Conforme visto, de acordo com esta, uma mudança no estoque de ouro (sem que vigore qualquer mecanismo de esterilização) provoca uma variação correspondente na demanda agregada (supondo que a velocidade de circulação da moeda seja insensível à mudança na sua quantidade), com efeito apenas sobre o nível geral de preços da economia (e não sobre a taxa de juros ou a produção), uma vez que a oferta é suposta como dada (lei de Say). Os adeptos do mercantilismo discordam da validade dessa teoria à medida que identificam que uma mudança na oferta de moeda terá repercussão sobre a taxa de juros, influenciando o nível de investimento e o fluxo de capitais. Portanto, na visão dos mesmos, um aumento na oferta de moeda tende a contribuir para aumentar a capacidade produtiva da economia, sendo o saldo superavitário da balança comercial condição indispensável para evitar constrangimentos oriundos de problemas no balanço de pagamento no contexto em que o fluxo de capitais é suposto relativamente baixo.

Os adeptos do mercantilismo defendem a implantação de políticas protecionistas porque não acreditam na operação do mecanismo de ajuste automático do câmbio, na validade da TQM - já que supõem que a variação na oferta de moeda tem impacto sobre a produção e emprego - e desconsideram a prevalência da condição de Marshall-Lerner. Na verdade, em alguns casos se pode supor mesmo a violação de tal condição: caso em que, por exemplo, uma valorização da taxa de câmbio real que, embora reduza a quantidade física exportada, permita o aumento do valor das exportações líquidas em função do efeito do aumento dos preços dos produtos exportados. Nesta situação o mecanismo de Hume, ao invés de contrabalançar, reforçaria a eficácia do protecionismo.

Smith e Ricardo acreditam nas vantagens proporcionadas pelo livre comércio. No caso de Smith, o comércio externo permite ampliar o mercado ao escoar o excedente de mercadorias que ultrapasse a demanda nacional, ao mesmo tempo em que a liberdade de transacionar garante o acesso em condições vantajosas aos produtos que não são produzidos internamente. Para Ricardo, através do livre comércio um país pode adquirir mercadorias mais baratas que podem reduzir o custo da força de trabalho e garantir a ampliação de lucros

\footnotetext{
${ }^{4}$ Esta condição supõe que uma valorização (desvalorização) da taxa de câmbio piora (melhora) o saldo da balança comercial em uma dada moeda quando o incremento que produz no valor das exportações é inferior (superior) ao aumento que provoca no valor das importações.
} 
que estenderão os limites da acumulação, atrasando a convergência para o estado estacionário. Contudo, os dois autores, ao contrário dos mercantilistas, parecem atribuir menor importância ao comércio internacional como condição de desenvolvimento de um país ${ }^{5}$. Grosso modo, os dois sistemas de análise têm em comum a consideração de que o motor do desenvolvimento de uma economia é o aumento do seu estoque de capital, que depende do nível de investimentos gerado pelo volume de poupança. O estoque de capital determina a oferta e as restrições ao crescimento não se encontram no lado da demanda, mas do nível de poupança formado a partir dos lucros.

Nesse sentido, em função dessas hipóteses e da operação do mecanismo de ajuste automático do balanço de pagamentos, é possível observar os motivos pelos quais as políticas protecionistas não geram efeitos macroeconômicos, ou seja, não promovem o aumento do estoque de capital, do emprego e da renda. Elas apenas constroem vantagens artificiais para alguns produtos em função da distorção que promovem nos preços relativos das mercadorias transacionadas no comércio internacional ${ }^{6}$.

Contudo, mesmo sendo adeptos do livre comércio, e desenvolvendo esquemas analíticos que mostram a coerência lógica dos resultados propostos, os referidos pensadores quando se deparam com questões concretas qualificam suas análises à luz de determinadas considerações. No caso de Smith, merece destaque sua antecipação do que contemporaneamente pode ser chamado de argumento da "segurança nacional", quando reconhece a legitimidade da adoção de políticas protecionistas que visam resguardar a "atividade necessária para a defesa do país", a exemplo da Lei sobre navegação inglesa, que justifica como uma resposta da Inglaterra à Holanda, pois "subsistia a animosidade mais violenta entre as nações". Na sua avaliação, as medidas propostas pela Lei "são tão sábias como se todas elas tivessem sido ditadas pela mais prudente sabedoria”(SMITH, 1776, p. 71). Assim, com base nesta citação é possível destacar que, na avaliação do autor supracitado, as razões de Estado superam as razões econômicas.

\footnotetext{
${ }^{5}$ Smith (1776, p. 282) ao analisar os diversos empregos dos capitais observa que o comércio interno gera um resultado melhor em termos de número de mão-de-obra empregada e valor da produção anual, do que o capital aplicado no comércio externo de bens de consumo, e este último produz um resultado melhor em termos daquelas duas variáveis que o capital empregado no transporte de mercadorias. É possível que essa visão de Smith estivesse relacionada com a baixa proporção que o comércio externo representava na época em termos da geração da riqueza nacional.

${ }^{6}$ Ao analisar os efeitos que uma política protecionista pode gerar, Smith $(1776$, p. 63) observa que uma reserva de mercado pode beneficiar algumas empresas e dirigir às atividades protegidas "um contingente maior de mãode-obra e de capital do que de outra forma seria empregado nela". Contudo, observa que tal canalização não promove necessariamente a ampliação "da atividade geral da sociedade que nunca pode ultrapassar aquilo que o capital da sociedade tem condições de empregar".
} 
O outro caso que para Smith justificaria a imposição de obstáculos à importação de mercadorias para incentivar o desenvolvimento da indústria nacional ocorreria quando os produtos fabricados pela mesma sofressem alguma taxação. Nas suas palavras, "parece razoável impor uma taxa igual ao produto similar do país estrangeiro" (SMITH, 1776, p.72). Smith discorda da proposta de estender a taxação às outras mercadorias importadas, e não apenas àquelas que concorrem com o produto similar nacional taxado, pois a generalização dessas tarifas ao incidir sobre os preços dos "artigos de maior necessidade" teria efeito sobre os salários, elevando o custo da mão-de-obra para todas as mercadorias. Quando examina a conveniência de retirada dos incentivos dados à produção de determinadas atividades, Smith propõe que o que hoje se chama de "abertura comercial" seja feita de forma cuidadosa e gradual, em um intervalo de tempo razoável e com a devida informação aos empresários que serão afetados. Desse modo, considera que a velocidade de supressão dos incentivos deve envolver um tempo necessário à preparação dos empreendedores para a mudança no ambiente concorrencial.

O mesmo argumento é empregado por Ricardo quando analisa as consequiências da interrupção das correntes comerciais provocada por uma guerra em um dado país, que o isola dos demais. Ao se referir à produção doméstica de produtos agrícolas (“trigo"), observa que o esforço empreendido para que a produção pudesse atender a demanda interna implicou aumento da sua oferta, a despeito do país não deter vantagens em termos de custo. O fim da guerra não deveria promover uma retirada imediata das barreiras à importação desse produto, pois "se tais esforços, realizados num período de emergência fossem seguidos pelo risco de ruína quando as dificuldades terminassem, o capital seria desviado de tal emprego". Desse modo, conclui:

[...] embora para a riqueza do país fosse mais vantajoso permitir a importação de trigo barato - independentemente do sacrifício de capital que isso possa ocasionar seria talvez recomendável lançar durante alguns anos uma taxa sobre a importação. (RICARDO, 1817, p. 185).

Outro aspecto interessante é que ao observar as diferenças de custo de produção em distintos países, Ricardo considera que aqueles que detinham vantagens absolutas deveriam atrair capitais e trabalho dos países que apresentavam desvantagens absolutas, em função da perspectiva de aumento da taxa de lucro que os primeiros ofereciam. Este fenômeno costumava suceder no interior de um mesmo país, o que terminava por garantir a equalização das taxas de lucro dos diversos capitais empregados em seu território. Contudo, tal resultado não se verificava no caso de diferentes países. Ele atribuía essa discrepância à dificuldade de 
imigração de capitais, ditada pela "insegurança real ou imaginária" de seus proprietários, fruto de sentimentos que incluíam o receio de abandono do país de origem e de submissão às novas leis e costumes e que ele "lamentaria ver enfraquecidos". (RICARDO, 1817, p. 105).

É interessante notar que tal processo mantém a taxa de lucro na Inglaterra abaixo (e, portanto, o salário real acima) do que ela seria num contexto de maior mobilidade de capitais, uma vez que uma maior saída de capitais, em busca das taxas de lucro superiores no exterior, acarretaria uma elevação da taxa de lucro doméstica (redução do salário real). Portanto, a visão comumente divulgada de Ricardo como defensor extremo dos interesses dos capitalistas industriais é, pelo menos nesse aspecto, falsa.

Malthus (1820) parece estar mais próximo dos mercantilistas do que das posições de Smith e Ricardo. Não por acaso Keynes (1936, p. 43) faz elogios à percepção que ele tinha do problema de insuficiência de demanda efetiva ${ }^{7}$, e tece argumentos no capítulo XXIII da referida obra para mostrar porque as idéias mercantilistas são defensáveis.

Mas o que a leitura de certos detalhes das obras de autores clássicos como Smith e Ricardo mostra é que ainda que suas teorias façam a defesa do livre comércio, eles não parecem desconsiderar inteiramente aspectos relacionados à geopolítica, como uma leitura liberal descuidada pode suscitar. Por outro lado, as ideias mercantilistas parecem incorporar definitivamente a questão do Estado e do poder, tanto direta quanto indiretamente, através da preocupação com as restrições que o balanço de pagamentos pode trazer ao desenvolvimento.

\section{Acumulação de capital na economia política clássica: Princípio da demanda efetiva $\mathbf{x}$ lei de Say}

Em decorrência principalmente do fato dos autores terem utilizado diferentes princípios estruturantes nas suas teorizações acerca do processo de acumulação de capital - a saber, o "princípio da demanda efetiva" ou o "princípio de Say"8, inexiste uma formulação teórica comum entre os mesmos sobre tal processo.

\footnotetext{
${ }^{7}$ Keynes observa que a incapacidade de Malthus fornecer uma estrutura lógica que explicasse com clareza sua oposição às ideias de Ricardo sobre a impossibilidade "de insuficiência de demanda efetiva" contribuiu para que este último autor conquistasse "a Inglaterra de maneira tão completa como a Santa Inquisição conquistara a Espanha. Sua teoria não só foi aceita pelos meios influentes de Londres, pelos estadistas e pelo mundo acadêmico, como também cessou toda a controvérsia, e o ponto de vista contrário desapareceu por completo e deixou de ser discutido" (KEYNES, 1936, p. 43).

${ }^{8} \mathrm{O}$ princípio de Say é normalmente denominado na literatura econômica de "lei de Say".
} 
A literatura contemporânea que aborda tais princípios enfatiza que o seu conteúdo essencial diz respeito ao sentido da determinação existente entre a renda e a demanda em nível agregado e não no nível de mercados específicos (MACEDO, 1999; POSSAS, 1987).

Com base na "lei de Say", que enuncia que "toda oferta gera sua própria procura", a economia é regida pela oferta. Logo, o sentido da determinação é da renda (oferta) para a demanda. Segundo este princípio, ao ser criado um produto, cria-se, ao mesmo tempo, uma demanda de igual magnitude. Ademais, como de acordo com essa teoria, é pressuposto que a função precípua da moeda é de mera intermediária das trocas, se o possuidor de renda não a gasta em consumo ou investimento, deverá emprestar a parte não gasta a outrem que a dispenderá. Desse modo, toda a renda gerada no ato da produção deverá ser necessariamente gasta.

Por outro lado, segundo o "princípio da demanda efetiva" se um ato de compra corresponde efetivamente a um ato de venda, a simultaneidade de ambos os atos decorre da decisão autônoma do agente que efetua o gasto, pois se um agente econômico pode decidir quanto gastar, não pode decidir quanto receber. Assim, o sentido da determinação é do gasto (demanda) para a renda (oferta). Evidentemente, a diferença no sentido da determinação renda/gasto implicará distintas explicações dos fenômenos econômicos, ou seja, conforme se adote a "lei de Say" ou o "princípio da demanda efetiva".

No que concerne à utilização clássica de tais princípios, é necessário destacar que embora somente tenha sentido fazer referência à "lei de Say" a partir do início do século dezenove, a idéia da "lei" fora utilizada como um dos princípios estruturantes da teorização econômica elaborada por Smith na "A riqueza das nações" (1776) e por Ricardo nos "Princípios de economia" (1817). Nesses autores, constitui-se idéia comum a necessidade de poupança prévia como condição para que ocorram adições à capacidade produtiva da economia e, por conseguinte, para que se processe o crescimento econômico.

Segundo Smith (1776), a produção (oferta) constitui-se fonte de todos os rendimentos, mas os lucros especificamente constituem a base que propicia a acumulação (poupança) que permite promover a ampliação da capacidade produtiva (estoque de capital), desencadeando o processo de crescimento da economia. A ampliação do estoque de capital promove a elevação da demanda de força de trabalho, implicando elevação do salário de mercado e, por esse motivo, desencadeia um movimento de ampliação, a longo prazo, do tamanho da população. Da ampliação do estoque de capital e da contratação de trabalhadores resulta nova ampliação da produção (oferta). A elevação dos rendimentos decorrente dessa ampliação implica 
também aumento da extensão do mercado que, na concepção smithiana, consiste condição essencial para o aprofundamento da divisão do trabalho que, por sua vez, se traduz em aumento da destreza e da habilidade do trabalho e no progresso tecnológico, promovendo ganhos de escala que induzem o crescimento da economia. Para Smith, os efeitos decorrentes da ampliação do estoque de capital e da produtividade, expressão do aprofundamento da divisão do trabalho, provocam um movimento cumulativo na atividade econômica. Assim, pode-se afirmar que Smith tinha uma perspectiva otimista para o futuro da acumulação, do crescimento e do bem-estar social. Na realidade, sua visão otimista sobre o futuro da acumulação de riqueza baseava-se, adicionalmente, na existência de um sistema econômico baseado na livre concorrência, no funcionamento do sistema de preços e na liberdade para os indivíduos buscarem seus interesses egoístas, de modo a promover o bem-estar social. Para tanto, deveriam ter vigência a lei de Say, o dinheiro desenvolvendo a função precípua de intermediário das trocas e a teoria quantitativa da moeda. Não obstante tal otimismo, é importante ressaltar que Smith vislumbrou a possibilidade de se atingir um estado estacionário, conforme será aprofundado no terceiro item deste trabalho ${ }^{9}$.

A lei de Say constituiu-se também em princípio estruturante dos "Princípios de economia" de Ricardo. No capítulo intitulado "Efeitos da acumulação sobre os lucros e o juro", Ricardo demonstra que ainda que possa ocorrer excesso de capital em segmentos econômicos específicos, o mesmo não pode ocorrer para o conjunto da economia. Segundo o autor, "a procura é somente limitada pela produção", de modo que um possuidor de renda ou a emprega produtivamente ou em consumo ou a empresta a alguém para o mesmo fim, uma vez que a moeda serve apenas para utilização como meio de troca. Desse modo, produção em excesso somente pode existir em caso de determinadas mercadorias, porém "não pode acontecer com todas as mercadorias" (RICARDO, 1817, p. 198). Fazendo alusão a determinada passagem da obra de Smith, destaca que a natureza impõe limites apenas ao capital que pode ser utilizado na agricultura, uma vez que o estômago é limitado pelas suas

\footnotetext{
${ }^{9}$ Smith (1776, p. 161) observa que quando a produção de qualquer setor exceder a demanda interna, deve ser exportado, pois "sem tal exportação uma parte do trabalho produtivo de um país deve cessar, e o valor de sua produção anual deve diminuir" (grifo nosso). Esta passagem, segundo a qual as exportações levam ao uso de recursos que de outra maneira permaneceriam ociosos, foi denominada por Mynt (1958) de "canal de escoamento do excedente" e constitui, em nossa opinião, no único trecho em todo o livro no qual Smith realmente parece, em contradição com o resto do livro, adotar o princípio da demanda efetiva. Cabe ainda ressaltar que esta passagem, bem como o uso freqüente da expressão "demanda efetiva", fizeram com que alguns autores tais como, por exemplo, Davidson (1994, p. 241) e Thweatt (1994) afirmassem que Smith foi usuário do princípio da demanda efetiva. Contudo, acreditamos que, com exceção do trecho em questão, todos os demais usos do termo se referissem a exemplos microeconômicos, nos quais, de forma perfeitamente compatível com a lei de Say, a demanda setorial determina as quantidades produzidas.
} 
próprias dimensões. Porém, tais limites inexistem com relação ao capital "que pode ser aplicado na produção de comodidades e artigos de luxo para a existência humana" (RICARDO, 1817, p. 199). Então, enquanto propiciar lucros, a produção deverá prosseguir seu curso normalmente até o momento em que uma queda permanente dos lucros freie a acumulação e a produção. De acordo com Ricardo, somente a elevação também permanente dos salários é capaz de provocar tal situação. Ademais, argumenta que uma elevação desta natureza somente poderia ocorrer associada ao aumento das dificuldades para a expansão da produção de gêneros alimentícios, conforme será melhor abordado no item seguinte.

Abordada a perspectiva clássica da acumulação, destacam-se, a seguir, as implicações da adoção da lei de Say para uma esfera específica da vida econômica: o mercado de trabalho. Conforme já aludido anteriormente, com base na lei de Say não tem sentido a ocorrência de excesso de capital na economia como um todo, uma vez que toda renda acaba sendo gasta, direta ou indiretamente, neste último caso através de empréstimos a quem vai gastar.

Segundo os clássicos, com base na lei de Say também não tem sentido existir excedente no mercado de trabalho em termos globais e a longo prazo. A idéia nesses autores é que a dinâmica da população e da força de trabalho é subordinada à dinâmica da acumulação. Portanto, na medida em que se expande o estoque de capital, amplia-se a demanda por trabalhadores, fazendo com que o salário de mercado se situe tendencialmente em nível superior ao do salário natural, induzindo ao crescimento da população e, por conseguinte, da força de trabalho. Assim, como consequência pode ocorrer além de desemprego temporário de uma parcela da força de trabalho, piora das condições de vida dos trabalhadores que continuam empregados. Desse modo, o "ajustamento" da população e da força de trabalho ao processo de acumulação, a longo prazo, dá-se pela eliminação literal de parte da população. Portanto, percebe-se que o uso da lei de Say segundo os clássicos implica na plena utilização da capacidade produtiva da economia, que, por sua vez, estabelece o nível da demanda por mão-de-obra. Entretanto, a plena utilização de capacidade não implica necessariamente eliminação do desemprego, já que pode persistir por muito tempo o descasamento entre tamanho da força de trabalho e a quantidade de emprego que pode ser gerada a partir do estoque de capital existente, com o mecanismo de ajuste sendo meramente tendencial. É importante ressaltar que esta é uma consequiência teórica completamente diferente da que resulta do uso da lei de Say na teoria neoclássica sobre o mercado de trabalho. Nessa elaboração teórica, a utilização da lei de Say implica pleno emprego da mão-de-obra, pois como o ajustamento ocorre via flexibilidade de salários, a idéia é que todo o desemprego 
deverá ser eliminado, a menos que forças extraeconômicas atuem desvirtuando o pleno funcionamento do mercado de trabalho.

Uma vez abordada a utilização da lei de Say na economia política clássica, através de Adam Smith e David Ricardo, será enfocado o uso do princípio da demanda efetiva, através de Thomas Malthus.

Nos seus "Princípios", ao discutir o "progresso da riqueza", Malthus examina os determinantes do desenvolvimento econômico, tanto pelo lado da capacidade produtiva (oferta), quanto pelo lado da demanda efetiva. Do lado da oferta são apresentados três determinantes para o aumento da capacidade produtiva: a acumulação de capital, a fertilidade do solo e o progresso técnico. Esses determinantes trabalham na mesma direção, mas por não proporcionarem estímulo adequado ao crescimento contínuo da riqueza, é fundamental, para assegurar tal ocorrência, o aumento permanente da demanda.

O desejo capitalista de acumular explica-se pelo desejo de aumentar os lucros. Para que isso é preciso que haja o aumento da demanda efetiva. Ao analisar a questão de como aumentar a demanda Malthus contrapõe-se à Lei de Say, mostrando que seus defensores incorreram em três erros: desprezaram as características próprias das mercadorias em relação às demandas específicas dos consumidores; supuseram que toda a renda seria gasta e acreditaram que a acumulação de capital garantiria a demanda para a produção adicional. Criticando Say, rejeita a afirmação de que a simples produção de mercadorias aumenta proporcionalmente a demanda, pois não se troca mercadoria por mercadoria e sim por trabalho produtivo ou improdutivo. Alerta Malthus que independentemente da mudança existente na relação entre as mercadorias, pode ocorrer alteração na necessidade delas por parte da sociedade ou na relação delas com o ouro ou ainda entre o trabalho nacional e o estrangeiro implicando, assim, saturação momentânea de uma mercadoria em seu respectivo mercado. Nesse último ponto há uma concordância de Malthus com Ricardo, embora as motivações para a saturação não sejam coincidentes entre os respectivos pensadores.

Segundo Malthus, a demanda efetiva consiste em "uma demanda por parte daqueles que estão aptos e dispostos a pagar um preço adequado pelas mercadorias" (MALTHUS,1820, p. 199-200), sendo também três os seus determinantes, quais sejam: a divisão da propriedade da terra, o comércio interno e externo e o consumo dos trabalhadores improdutivos. Para o autor, a redivisão da propriedade da terra seria importante, pois a sua concentração tenderia a provocar também concentração de renda, o que, por sua vez, obstaculizaria a objetivação de uma demanda efetiva pujante. Por isso, uma renda 
relativamente menos concentrada, permitiria uma demanda efetiva favorável à acumulação de riqueza no país. Da mesma forma, o aumento dos salários contribuiria para ampliar a demanda efetiva. Fazendo referência ao caso da Irlanda, Malthus mostra que as restrições e dificuldades enfrentadas pela manufatura nesse país eram muito mais uma decorrência da falta de demanda do que de capital, pois, segundo suas palavras "a demanda geralmente produz capital, embora nem sempre o capital gere demanda" (MALTHUS, 1820, p. 211).

O comércio - interno e externo - constituiria a segunda principal causa favorável à elevação do valor de troca da produção que, por sua vez, dependeria principalmente da “distribuição de mercadorias mais bem adaptadas às necessidades e gostos da sociedade" (MALTHUS, 1820, p. 236). O comércio externo completaria o comércio interno que constitui-se, por sua vez, na primeira fase para o aumento da riqueza de qualquer país.

Malthus aproxima-se dos pensadores mercantilistas, ao defender que é a ampliação do comércio exterior que leva diretamente à importação de ouro. Essa importação colabora para o aumento da riqueza, pois ao entrar no país, aumenta a oferta monetária que não necessariamente gera inflação, porque tende a aumentar a capacidade produtiva para fazer face à demanda. A tendência natural do comércio exterior consiste no aumento imediato do valor e consequentemente dos lucros, sem que necessariamente ocorra uma redução proporcional do comércio interno. Em outras palavras, a demanda externa constitui-se em importante via para o aumento da produção e da riqueza. Tal pensamento ratifica a discordância de Malthus com a Lei de Say, pois ratifica a visão de que a demanda cria a oferta e não o inverso.

"A terceira principal causa que tende a manter e aumentar o valor do produto, por favorecer sua distribuição, é o emprego de trabalho improdutivo" (MALTHUS, 1820, p. 250). Percebe-se que o autor antecipa em décadas a idéia de que quando os capitalistas estão poupando muito ou quando a substituição de máquinas por homens é muito intensa, é necessário que um país possua consumidores improdutivos para que não ocorram desajustes entre a produção e a demanda efetiva. Nesse sentido, os trabalhadores improdutivos tornam-se fundamentais para a manutenção da demanda e consequentemente ao "equilíbrio" do sistema. Ele ressalta a importância de tais consumidores, pois entende que o consumo dos trabalhadores produtivos não se constitui em um tipo de consumo que leva à riqueza de um país. Assim, se:

[...] os industriais não têm vontade de consumir o suficiente, e se os trabalhadores não têm a capacidade de fazê-lo, e se a contribuição dos proprietários de terra não se 
mostra suficiente, o consumo necessário tem de ocorrer entre os trabalhadores improdutivos de Adam Smith (MALTHUS, 1820, p. 256).

Com o propósito de solucionar este problema defendia a elevação dos gastos públicos, que teriam a capacidade de gerar demanda adicional.

É importante destacar que indagando Malthus com ironia, Ricardo escreve nas suas famosas notas aos "Princípios de Malthus":

Se o próprio povo não gasta o suficiente, o que seria mais conveniente do que obrigar o governo a gastar por ele? O que poderia ser mais sensato, se a teoria do Sr. Malthus fosse correta do que aumentar o exército e dobrar os salários de todos os funcionários do governo? (RICARDO EM MALTHUS, 1820, p. 268).

Certamente Malthus responderia positivamente sobre a necessidade dos gastos governamentais ativarem o nível da demanda, porém quanto à agenda, dependeria da situação. Nas palavras de Malthus (1820, p. 268): “É dever dos governos evitar a guerra, quando possível; mas se ela é inevitável, é dever dos governos regular as despesas, de modo a produzir a menor flutuação possível da demanda". Entretanto, destaca que "os interesses da grande maioria da sociedade requerem paz e despesas regradas" (MALTHUS, 1820, p. 269), portanto identifica no governo um agente fundamental para a condução da política econômica também em períodos de paz. Além da defesa de tal papel para o governo, o autor supracitado, em aparente oposição com o posicionamento que adotou no "Ensaio sobre a população" defende melhorias salariais por motivos não estritamente econômicos: "É desejável que as classes trabalhadoras sejam bem pagas, e por uma razão mais importante que aquela relacionada à riqueza, a saber, a felicidade da grande maioria da sociedade" (MALTHUS, 1820, p. 255).

Por fim, destaca-se que embora os clássicos apresentem teorias diferentes sobre o processo de acumulação, em decorrência da utilização da lei de Say ou do princípio da demanda efetiva, e cheguem a partir delas a conclusões distintas acerca da atuação do Estado na economia, as leituras reducionistas exageram tal diferença no campo normativo (vide Considerações Finais), contribuindo para uma despolitização adicional do debate. Ademais, há outros traços em comum nesses autores, como, por exemplo, o vislumbre da possibilidade de se atingir um estado estacionário, a partir da concepção da finitude dos recursos naturais frente ao crescimento da produção e da demanda - o que é objeto de discussão no item seguinte. 


\section{Limites ao crescimento econômico colocados pela disponibilidade de recursos naturais}

Do anteriormente descrito, fica claro que para a economia política clássica inglesa o crescimento econômico é liderado pela acumulação de capital, e não encontra limites nem na disponibilidade de mão-de-obra, nem nas restrições de balanço de pagamentos. Antes pelo contrário, tal escola oferece razões para que o crescimento populacional seja determinado pelo crescimento do estoque de capital, bem como para que o balanço de pagamentos se equilibre automaticamente através do mecanismo descrito inicialmente por Hume (1752). Como também visto, há controvérsias acerca da possibilidade do processo de acumulação de capital esbarrar em limitações de demanda efetiva (MALTHUS, 1820) ou, alternativamente, da disposição de poupar (SMITH, 1776; RICARDO, 1817). Contudo, para além do debate, existe certo consenso entre esses três autores de que o crescimento econômico cedo ou tarde encontraria um limite na disponibilidade de recursos naturais não-reprodutíveis, em particular na fertilidade e distância das terras e das minas. O presente item se dedica a discutir as peculiaridades em que este aspecto aparece nestes três autores, e as implicações para as respectivas visões sobre o crescimento econômico e a distribuição de renda. Em tempos de aquecimento global e proclamações acerca do (suposto) breve esgotamento de recursos naturais não renováveis cruciais, como água e petróleo, a questão se reveste de contemporaneidade e importância inegáveis.

Em Smith, como visto, o crescimento é um processo liderado pela disposição a poupar, que se acelera em função dos ganhos de escala dinâmicos propiciados pela crescente divisão do trabalho, realimentando o próprio crescimento. Contudo, por trás da visão otimista sobre este processo, já existe um limite ao crescimento, um estado estacionário caracterizado pelo esgotamento da disponibilidade de recursos naturais. Fortemente eclipsada pela exuberante descrição do processo de crescimento, tal estado aparece mais como uma possibilidade do que um limite efetivo, embora adquira alguma concretude no contexto da discussão do caso chinês (SMITH, 1776, p. 67):

\footnotetext{
A China foi por muito tempo um dos países mais ricos, isto é, dos mais férteis, mais bem cultivados, mais industriosos e mais populosos do mundo. Ao que parece, porém, há muito tempo sua economia estacionou (...). Talvez tivesse conseguido aquele complemento pleno de riqueza que a natureza e as leis e instituições permitem adquirir.
}

Smith observa que no caso chinês leis e instituições "imperfeitas" poderiam ter adiantado a chegada a esse estado estacionário. O tema reaparece no capítulo seguinte de forma mais clara (SMITH, 1776 p. 84): 
Em um país que tivesse adquirido toda a riqueza compatível com a natureza de seu solo e clima e com a localização em relação a outros países, e que portanto não tivesse mais possibilidade de progredir [...] aconteceria o seguinte: tanto os salários do trabalho quanto os lucros do capital seriam provavelmente muito baixos. Em um país totalmente povoado, tanto em relação ao território necessário para manter essa população, quanto ao capital necessário para dar-lhe emprego, a concorrência para conseguir emprego necessariamente seria tão grande que reduziria os salários ao estritamente necessário para conservar o número de trabalhadores, sendo que este número jamais poderia ser aumentado, pois o país já estaria, no caso, totalmente povoado. Em um país saturado de capital, em relação a todos os negócios a transacionar, esse montante tão alto de capital seria aplicado em todo e qualquer setor específico que a extensão do comércio comportasse. Em conseqüência, a concorrência seria em toda a parte a maior imaginável, e o lucro comum do capital seria igualmente o mais baixo possível. Talvez, porém, nenhum país tenha ainda chegado a esse grau de opulência.

Ademais, são os fatores naturais, como a natureza do clima e do solo, e a distância de outros países, que impõem um limite ao crescimento. Neste cenário a taxa de lucro seria baixa devido ao suposto aumento da pressão da concorrência resultante do elevado estoque de capital; enquanto os salários reais permaneceriam ao nível de subsistência, já que em uma economia em estado estacionário os níveis de estoque de capital, e, portanto, de emprego e população seriam constantes. Então, a renda da terra deveria ser relativamente elevada, absorvendo parte significativa do excedente. Isto condiz com a ideia, expressa alhures (SMITH, 1776, p. 59), de que:

\begin{abstract}
Certos produtos naturais exigem características tais de solo e localização que até mesmo todas as terras de um grande país aptas para a produção deles podem ser insuficientes para atender à demanda efetiva. Por conseguinte, todo o estoque colocado no mercado pode ser vendido àqueles que estão dispostos a dar pelo produto mais do que o suficiente para pagar, de acordo com suas taxas naturais, a renda da terra que os produziu, juntamente com os salários do trabalho e os lucros do capital empregados para prepará-los e colocá-los no mercado. Tais mercadorias podem continuar a ser vendidas a esses preços altos durante os sáculos seguidos; é a parte do preço que consiste na renda da terra que, nesse caso, é geralmente paga acima de sua taxa natural.
\end{abstract}

Smith parece estar tratando, portanto, de uma situação na qual a oferta agrícola tornase (crescentemente?) inelástica em função da indisponibilidade de terras a uma distância praticável dos mercados domésticos. Parece que, a partir de certo ponto, qualquer tentativa adicional de expansão da economia, ainda que como resultado de elevação da taxa de poupança, resultaria em expansão adicional simultânea do preço relativo dos produtos agrícolas e da renda da terra, em detrimento das demais classes sociais.

Desse conjunto de ideias, contudo, resultam alguns problemas. De fato, Smith apresentou dois motivos diferentes e desconexos para que a economia convergisse para o estado estacionário: a) a queda da taxa de lucro associada ao estoque crescente de capital; b) o aumento da renda da terra devido ao aumento do preço dos alimentos conforme se esgota a 
disponibilidade de terras férteis. Os dois pontos estão desconectados porque apenas por coincidência a disponibilidade de terras férteis se esgotaria exatamente no momento em que o estoque de capital atingisse o tamanho crítico, capaz de (supostamente) fazer a taxa de lucro baixar até zero. Ademais, ambos os pontos são problemáticos por si. O primeiro supõe que o aumento do estoque de capital reduza a taxa de lucro (questionavelmente) devido à pressão da concorrência. O último supõe a validade da (também questionável) teoria da renda da terra smithiana, segundo a qual:

Há certos produtos da terra para os quais a demanda deve sempre ser tal que permita
um preço superior ao que é suficiente para colocá-los no mercado; e outros há, para
os quais a demanda pode ou não ser tal que permita esse preço mais alto. Os
primeiros sempre devem proporcionar uma renda ao proprietário da terra. Os
segundos às vezes podem proporcionar tal renda e às vezes não, conforme as
circunstâncias. (SMITH, 1776, p. 122).

A partir da crítica a ambos os pontos, Ricardo (1817) desenvolve duas teorias virtualmente novas, uma para a renda da terra e outra para a tendência ao decréscimo da taxa de lucro, cuja interligação fornece uma rationale para a convergência para o estado estacionário inexistente em Smith.

O primeiro questionamento dirige-se à queda da taxa de lucro. Para Ricardo, a tendência de fato existe, mas a sua causa não é a pressão concorrencial crescente resultante do crescimento do estoque de capital. A verdadeira causa consistiria no fato de que o crescimento econômico (liderado pela acumulação de capital via poupança) implica a utilização de terras em ordem decrescente de fertilidade e/ou crescente de custos de transporte, de forma tal que a produtividade do trabalho na terra marginal também decresce conforme a fronteira agrícola se desloca. Como resultado, o crescimento econômico tende a ser acompanhado, coeteris paribus, pelo aumento do preço relativo dos produtos agrícolas e, portanto, do salário real de subsistência. A elevação deste, por sua vez, tornando-o temporariamente superior ao salário real efetivo, tenderia a elevar a taxa de mortalidade dos trabalhadores, reduzindo o crescimento populacional em relação ao crescimento da economia e do emprego. Isto tenderia a criar uma escassez temporária de mão-de-obra, a qual provocaria uma elevação corretiva dos salários reais efetivos e, portanto, uma queda da taxa de lucro e, a partir de certo momento, também de seu montante.

Ademais, este movimento de fato é acompanhado pelo aumento da renda nas terras não-marginais, a qual, porém, contrariamente a Smith, não pressiona diretamente a taxa de lucro. Tanto o aumento do salário real quanto o da renda da terra são resultantes do mesmo fenômeno: a dificuldade de ampliar a produção agrícola mediante o emprego de maior 
quantidade de um elemento heterogêneo e não-reprodutível, a terra. No limite, o salário real crescente acabaria por absorver todo o excedente, eliminaria o lucro e a poupança líquida a partir dele gerada, a qual era a responsável pela manutenção da expansão do estoque de capital e da economia. Por consequência, conduziria a economia ao estado estacionário, no qual, com o salário real enfim equiparado ao de subsistência, a população tampouco se expandiria.

Embora considerado na prática ainda "muito distante" por Ricardo (1817, p. 89), o estado estacionário parece à primeira vista bem menos virtual para este autor do que para Smith. O próprio Ricardo (1815, p. 208) previa, porém, que tal tendência histórica poderia ser atrasada indefinidamente: i) pelo aumento da produtividade agrícola associada ao avanço tecnológico e à introdução da maquinaria; ii) pela possibilidade de importar produtos agrícolas e minerais de países cujos recursos naturais apresentassem vantagens comparativas.

Em sua crítica à teoria ricardiana da renda da terra, Malthus (1820, cap. III) não foi bem sucedido, de modo que a mesma continua a ser utilizada - surpreendentemente, tanto por ortodoxos como por alguns heterodoxos - como explicação básica do fenômeno. A tentativa malthusiana de abandonar o referencial de equilíbrio e de rejeitar a distinção entre preços naturais e de mercado, ousada e inovadora em si, parece ter tido relativamente pouco impacto na história do pensamento econômico, em particular entre suas vertentes hegemônicas. E a discrepância entre as taxas potenciais de crescimento da população e da produção agrícola, tão propalada por Malthus (1798, cap. I), constitui justamente o elemento que, descrito pelo modelo ricardiano em outro nível de sofisticação teórica, põe em marcha os mecanismos econômicos que conduziriam ao estado estacionário.

Se Malthus equivocou-se na crítica à teoria ricardiana da renda da terra - e, portanto, de distribuição da renda -, porém, sua crítica à lei de Say, revigorada por Keynes (1936) também em outro nível de sofisticação teórica, se mantém. Também é preciso retomar a ideia mercantilista da possível existência de uma restrição de balanço de pagamentos ao crescimento econômico, enfatizada pela Cepal para o caso latino-americano e retomada contemporaneamente por Thirlwall (1979). Assim, fica sujeita a tais revisões a possibilidade presente nos clássicos (e mais bem desenvolvida por Ricardo) de que o esgotamento dos recursos naturais não-renováveis fosse eventualmente capaz de frear o crescimento econômico. É preciso rever o encadeamento lógico de conexões causais que liga os dois fenômenos em Ricardo à luz dessas contribuições heterodoxas. 
Contudo, tal revisão precisa ser cuidadosa, pois apenas parte dos elementos teóricos propostos por este autor encontra-se efetivamente sob questionamento. Assim, por exemplo, mesmo que o crescimento econômico seja liderado pela demanda, e não pela poupança, permanece o fato de que a expansão econômica encontrará terras crescentemente inadequadas e, portanto, subsiste a pressão altista prevista por Ricardo sobre o preço relativo dos produtos agrícolas, o salário real de subsistência e a renda da terra. Portanto, não é incompatível com o espírito da contribuição de Ricardo perceber que é a combinação de vantagens locacionais e de fertilidade que dita a ordem de ocupação das terras, e não exclusivamente a fertilidade. Então, a existência mundo afora de bolsões ainda inexplorados de terras de fertilidade superior pode perfeitamente atrasar o alcance do estado estacionário.

Desde os tempos de Stuart Mill, Ricardo tem sido muito criticado, tanto à esquerda quanto à direita, por supostamente ter acreditado na prevalência de tal efeito sobre a ação do progresso técnico. Este, operando em sentido contrário, tenderia a baratear cada vez mais os produtos agrícolas, impedindo que tal pressão altista se manifestasse. Resultaria um pessimismo indevido acerca do futuro do capitalismo. Um exemplo típico é Simonsen (1994, p. 311):

Contrariamente a Adam Smith, Ricardo era um futurólogo do pessimismo, inspirado pela pressão demográfica contra os rendimentos decrescentes. Felizmente, para a humanidade, Ricardo, Malthus e seus contemporâneos subestimaram duas forças: a do capital, como fator de produção capaz de substituir a mão-de-obra, e a do progresso tecnológico, que ensinou a driblar a lei dos rendimentos decrescentes na produção de alimentos.

Uma leitura cuidadosa de Ricardo, contudo, revela que o autor foi injustiçado a este respeito. Primeiro, porque a idéia de uma eventual convergência para o estado estacionário, como visto, já existia em Smith. Segundo, porque ele pressupôs explicitamente que a descrição do processo de convergência se dava em um contexto coeteris paribus no qual a tecnologia estava dada por hipótese; porém: i) apontava que o avanço tecnológico era um dos fatores que, ao aumentar a produtividade do trabalho, poderia atrasar indefinidamente tal convergência; ii) Ricardo não parece ter questionado a validade dos ganhos dinâmicos de escala propostos por Smith (nem mesmo na agricultura!), apenas apontou os limites do processo; tais ganhos operam também no sentido de contrabalançar o processo de convergência ao estado estacionário; iii) no famoso capítulo sobre a maquinaria, explicitava a hipótese de que a própria introdução dessa dependesse do nível do salário real; assim, opera outra força que contrabalança a tendência à convergência para o estado estacionário: quando os salários aumentam em termos reais em resposta ao esgotamento dos recursos naturais, há 
incentivo para a introdução de mais maquinaria, a qual elevaria a produtividade do trabalho, reduziria os preços dos alimentos, a renda da terra e os salários reais, e elevaria a taxa de lucro. Contudo, a nova aceleração do processo de crescimento resultante voltaria a pressionar a economia na direção do estado estacionário.

Diante dessas observações, não parece possível negar aprioristicamente a possibilidade teórica de que a expansão econômica continuada leve à exaustão (quiçá relativa) dos recursos naturais não renováveis, e que esta conduza a um aumento continuado do preço relativo dos alimentos e a uma elevação do salário real de subsistência e da renda da terra. Não parece impossível, tampouco, que o aumento contínuo do salário real de subsistência produzido por esse processo venha eventualmente a produzir uma queda do crescimento populacional (especialmente nas regiões mais pobres do planeta) e, conseqüentemente, uma elevação do salário real efetivo.

Não parece nada óbvio, portanto, que Ricardo tenha subestimado o impacto da tecnologia e do aumento do capital como elemento de substituição da mão-de-obra (via introdução de inovações poupadoras de trabalho). Contudo, os nexos lógicos seguintes do processo de convergência ao estado estacionário são mais delicados.

Mesmo que a elevação dos salários reais pressione a taxa de lucro para baixo - o que é inevitável no contexto da lei de Say em que Ricardo pensava, mas não no da validade do Princípio da Demanda Efetiva em que esta análise é conduzida ${ }^{10}$ - ainda assim não é certo que uma queda da taxa de lucro conduza necessariamente a uma redução da taxa de crescimento da demanda agregada e, portanto, da de crescimento econômico. A hipótese comportamental mais favorável a este resultado é a de que a taxa de investimento seja função inversa da taxa de lucro ${ }^{11}$. Contudo, embora parcela significativa de economistas heterodoxos se incline em prol desta hipótese, há também razões ponderáveis para negar a existência de uma relação geral entre ambas ${ }^{12}$.

Ademais, se a economia se encontrar em uma situação na qual seu crescimento esteja sendo restringido pela posição de seu balanço de pagamentos, então o vínculo entre taxa de

\footnotetext{
10 Se não há capacidade ociosa, um aumento dos salários reais em uma economia fechada pressiona inevitavelmente a taxa de lucro no sentido inverso. Contudo, suposta a existência de capacidade ociosa, uma ampliação do salário real, ao ampliar o consumo real dos trabalhadores, pode aumentar o grau de utilização da capacidade, tornando dúbio o efeito sobre a taxa de lucro.

${ }^{11}$ Ou de proxies desta, como eficiência marginal do capital, etc.

${ }^{12}$ Basicamente, o fato de que o investimento é explicado por alguma versão da teoria do acelerador, na qual o mesmo depende do grau de utilização da capacidade. Para uma argumentação contra a utilização da taxa de lucro como variável explicativa do investimento, vide Possas (1987, p. 265-6) e Serrano e Freitas (2007, p. 7).
} 
lucro e taxa de crescimento virtualmente se extingue ${ }^{13}$. Vale ressaltar, porém, que exatamente nesta circunstância a propriedade nacional da produção dos recursos naturais não-renováveis e em vias de exaustão pode ser de grande valia para a manutenção do crescimento, na medida em que sua valorização pode ser um dos fatores que permita relaxar tal restrição.

E mesmo que afinal no caso mais geral o crescimento econômico consiga permanecer imune ao cenário ricardiano de esgotamento dos recursos naturais não renováveis, percebe-se que a pressão sobre o preço relativo dos alimentos pode tornar o processo de crescimento muito desfavorável aos trabalhadores. Cabe lembrar que durante uma fase de duração em princípio indefinida e possivelmente bastante longa, os salários reais tornam-se inferiores aos de subsistência, acarretando a operação de um mecanismo de reequilíbrio que opera através do aumento da taxa de mortalidade dos trabalhadores mais pobres. Neste contexto, a propriedade nacional da produção dos recursos naturais não-renováveis e em vias de exaustão também pode ser estratégica, pois a capacidade de redirecionar a venda de tais recursos do mercado externo para o interno pode se tornar fundamental para bloquear a concentração da renda, e no limite, preservar a vida de milhões de pessoas.

Assim, no campo das relações entre crescimento, distribuição e a utilização de recursos naturais não renováveis, uma leitura pouco atenta dos clássicos conduz a uma aceitação apressada da idéia de que a posição dos defensores da propriedade nacional de tais recursos carece de suporte teórico. Acaba, portanto, também nesta arena, por aumentar o grau de despolitização dos temas econômicos e a conduzir a uma interpretação equivocada de temas fundamentais ao desenvolvimento de povos, países e regiões.

\section{Considerações Finais}

Todos os três temas da Economia Política Clássica aqui tratados pertencem ao universo de debates recorrentes da Teoria Econômica, cuja contemporaneidade é intermitentemente questionada e retomada com entusiasmo. Esmiuçados, repisados, reexaminados sob os mais diversos ângulos, atualizados à luz das técnicas e métodos em voga, sua permanência por dois ou quase três séculos de História do Pensamento Econômico diz muito a respeito da natureza do raciocínio econômico e da sensibilidade das temáticas tratadas. Mostram-se neste particular como áreas nas quais ciência, ideologias e interesses se interceptam e sobrepõem, produzindo um debate cuja duração e veemência é, por si só,

13 Nesta situação, a taxa de crescimento passa a depender essencialmente das taxas de crescimento das exportações e das importações, ambas em princípio independentes da taxa de lucro. 
extremamente reveladora da natureza do jogo. Aqui, a ciência econômica toca em nervos expostos do tecido social, nos quais a opacidade usual das relações de dominação resulta perturbada pelo próprio burburinho reinante em torno dos temas.

Não foi a intenção deste artigo se embrenhar na caudalosa literatura que cerca cada um destes debates, mas sim desbordá-los nos originais pelo prisma da geopolítica do desenvolvimento. $\mathrm{O}$ intuito foi tentar recuperar nesses originais certos aspectos dos debates que são fundamentais para a compreensão do processo de negação da essência política da economia que segue, conforme a tese de Fiori (1999), seu próprio processo de autonomização enquanto ciência, em suas origens liberais clássicas. Tratou-se, no fundo, de procurar compreender como as leituras descuidadas e reducionistas - frequentemente de segunda mão dos autores clássicos envolvidos em tais debates acabam depositando sobre o nervo exposto camada sobre camada de verniz, como se o tecido social lançasse mão de um instrumento de auto-preservação no intuito de restaurar-lhe a opacidade original.

Lancetando a ferida, iniciou-se pelo exame do debate que envolveu a defesa do livre comércio por Smith e Ricardo contra a tese oposta dos mercantilistas e de Malthus. Fica de fato clara a proposta liberal no sentido de que o Estado abandone as políticas mercantilistas/protecionistas que constituíam a arena do conflito econômico internacional, bem como a essencialidade do funcionamento do mecanismo automático de equilíbrio do balanço de pagamentos de Hume para que isso ocorra. Contudo, as pré-condições necessárias para o funcionamento desse mecanismo prescrito por Hume parecem excessivas, de modo que a ação do Estado no campo econômico volta ao centro do palco para dar conta de buscar, pela administração da política econômica, o objetivo de controle das contas externas, o qual aparentemente não pode ser gerado automaticamente, apenas pelo funcionamento puro dos mercados. Assim, em uma leitura mais cuidadosa se percebe que, a despeito da defesa teórica (e retórica) do livre comércio, há sempre uma lista ou conjunto de exceções à regra geral (particularmente ampla no caso de Smith) que acaba por comprometer o princípio. Tais exceções são via de regra justificadas por razões de Estado ou segurança nacional, que acabam por se configurar em situações nas quais ocorre uma espécie de "repolitização da economia pela porta dos fundos", onde questões relacionadas ao poder falam mais alto que as razões estritamente econômicas.

A seguir, procedeu-se à releitura do debate sobre a lei de Say (Ricardo, Smith) e o princípio da demanda efetiva (Malthus, mercantilistas). Tais princípios antagônicos de interpretação da determinação dos níveis de produção e emprego trazem em si visões também 
polares acerca da capacidade de o Estado afetar tais variáveis - tanto diretamente, pela ação das despesas e transferências governamentais, quanto indiretamente, através de políticas voltadas à geração de superávits comerciais. A adoção da lei de Say pelos autores liberais conduz a uma visão negativa sobre a capacidade do governo ampliar produção e emprego, enquanto o princípio da demanda efetiva defende a posição contrária. Em princípio, portanto, o uso da lei de Say como instrumento analítico seria condizente com o afastamento do Estado da economia preconizado pelos liberais e a despolitização da mesma. Em particular, porque o exercício de soberania política implícito no ato de emitir moeda era visto no contexto da Teoria Quantitativa da Moeda - a teoria monetária compatível com a lei de Say - e do sistema monetário internacional então vigente (padrão-ouro) como exercendo efeitos apenas sobre as variáveis nominais, sem efeito real sobre a economia.

Todavia, uma leitura cuidadosa deste debate permite inferir a existência de uma série de frestas nesta dicotomia, quais sejam: a) como a lei de Say para os clássicos tem um sentido diferente do que para os neoclássicos, a ação do Estado sobre o crescimento econômico ainda pode se fazer sentir, através da manipulação da taxa de acumulação governamental; portanto, mesmo a lei de Say e a Teoria Quantitativa da Moeda não são suficientes para neutralizar completamente a ação econômica do Estado, embora a direcionem para um sentido diferente das propostas mercantilista e malthusiana; b) Smith deixa claro - sem contestação pelos demais liberais - que a ação egoísta individual não é per se suficiente para a organização de uma economia bem sucedida, ainda que estritamente nos moldes liberais, sendo a ação do Estado fundamental na criação das pré-condições institucionais necessárias para o exercício de uma espécie de "egoísmo esclarecido", ou limitado; c) a tentativa smithiana de justificar as exportações como benéficas através do "canal de escoamento do excedente" não é compatível com a lei de Say, mas sim com o princípio da demanda efetiva, o que permite pensar a ação do Estado, pelo menos neste particular, de forma bastante distinta.

Finalmente, o exame da existência de um estado estacionário, tanto em Smith quanto em Ricardo e Malthus, revelou nas entrelinhas que o possível esgotamento de alguns recursos naturais não-renováveis, a despeito de indefinido e apenas no campo das possibilidades, clama pela politização do tema do controle nacional de tais recursos, dadas as consequências previstas pela própria teoria clássica. Trata-se agora de que, ao invés de tratar o assunto do ponto de vista dos países que, como a Inglaterra, eram hegemônicos e importadores de alimentos e matérias-primas, mas sob o ângulo dos países subdesenvolvidos produtores de tais recursos (como os latino-americanos). 
Assim, se parece inegável que

[...] o viés político-ideológico imposto pela luta do liberalismo econômico contra o "sistema mercantil" impediu os economistas políticos ingleses de reconhecerem o que havia de verdade na política mercantilista e acabou enviesando, de forma definitiva, todo o pensamento econômico clássico (FIORI, 1999, p. 49).

Pelos motivos acima mencionados, parece haver alguma razão para aumentar o grau de crença associado à hipótese de partida do texto: em cada um dos debates acima mencionados, parece ter havido uma extrapolação ou radicalização da despolitização liberal da economia pela leitura descuidada dos detalhes dos economistas clássicos.

Tais exageros são particularmente graves no caso de Smith, o qual, como visto, foi "vendido" como campeão do liberalismo, mas pode ser facilmente interpretado com um "nacionalista pragmático", dada a extensa lista de qualificações ao livre comércio. Visto também de forma equivocada como um otimista inveterado sobre o futuro do capitalismo, assinalou a possibilidade de bloqueio ao crescimento continuado pelo estado estacionário e, no limite, sua reversão.

Ricardo, contrariamente, foi caricatamente descrito como um pessimista aferrado ao estado estacionário, incapaz de entender a capacidade da tecnologia de libertar o crescimento das limitações postas pelas restrições de recursos naturais não renováveis. Pelo aqui visto, porém, o estado estacionário para Ricardo era indefinidamente postergável por vários mecanismos, inclusive a evolução tecnológica. Visto como defensor dos capitalistas industriais, defendeu ideias contrárias aos interesses destes, e suas ideias no campo da distribuição de renda se tornaram inspiração para a vertente neoricardiana, por serem perfeitamente compatíveis com o princípio da demanda efetiva e com a defesa dos interesses dos trabalhadores.

Malthus foi outro autor tratado como "inimigo dos trabalhadores" de forma possivelmente exagerada. Se seus escritos mais jovens revelam a tendência a atribuir aos trabalhadores indevidamente a culpa pela sua própria pobreza e a negar assistência estatal aos necessitados, seus escritos mais maduros revelam outro nível de apreensão da questão. Ademais, no campo do debate com Ricardo, suas posições em prol da proteção estatal aos produtores de cereais e da ação no sentido do fortalecimento da demanda efetiva são sempre justificadas com vistas à preocupação com o emprego e o salário real dos trabalhadores, e não apenas dos proprietários de terras.

Tentativas, tanto à esquerda quanto à direita, de caricaturar os economistas clássicos, ora como campeões do liberalismo, defensores do egoísmo exacerbado e do Estado mínimo; 
ora como inimigos dos trabalhadores, desumanos e vendidos aos interesses dos capitalistas, além de injustas e maculadoras da probidade científica, padecem do mesmo mal de desviar o foco de atenção do ponto crucial que eles têm em comum: a defesa dos interesses imperiais britânicos, por todos eles promovida em alguma medida. Não é outra a questão por trás da despolitização.

\section{Referências}

DAVIDSON, P. Post Keynesian Macroeconomic Theory: A Foundation for Sucessful Economic Policies for the Twenty-firts Century. Aldershot: Edward Elgar, 1994.

DEYON, P. (1969). Le Mercantilisme. Tradução para o português: O mercantilismo. São Paulo: Editora Perspectiva S.A, 1973.

FIORI, J. L. (org.). Estados e moedas no desenvolvimento das nações. Petrópolis: Vozes, 1999.

GONÇALVES, R; et al. A Nova Economia Internacional: uma perspectiva brasileira. Rio de Janeiro: Campus, 1998.

HUME, D. (1752). Writings on Economics. Madison: The University of Wisconsin Press, 1970. Tradução para o português: Escritos sobre Economia. Coleção Os Economistas. São Paulo: Abril Cultural, 1982.

KEYNES, J. M. The General Theory of Employment, Interest and Money. Londres, Macmillan, 1936.

MACEDO E SILVA, A. C. Macroeconomia sem equilíbrio. Petrópolis: Vozes; Campinas: FECAMP, 1999.

MALTHUS, T. R. (1798) An Essay on the Principle of Population. Londres: J. Johnson, in St. Paul's Church-yard. Tradução para o português: Ensaio sobre a População. Coleção Os Economistas, $2^{a}$ edição. São Paulo: Nova Cultural, 1986.

MALTHUS, T. R. (1820) Principles of Political Economy Considered with a View to Their Practical Application. Tradução para o português: Princípios de Economia Política. Coleção Os Economistas, 2ª edição. São Paulo: Nova Cultural, 1986.

MYNT, H. The 'Classical Theory' of International Trade and the Underdeveloped Countries. Economic Journal, 68, págs. 317-337, 1958.

POSSAS, M. L.. A Dinâmica da Economia Capitalista: uma abordagem teórica. São Paulo: Brasiliense, 1987.

RICARDO, D. (1815). Essay on the Influence of a Low Price of Corn on Profits of Stock". Tradução para o português: Ensaio acerca da influência do baixo preço do cereal 
sobre os lucros do capital. In: Napoleoni, Claudio Smith, Ricardo e Marx, $2^{\mathrm{a}}$. edição. Rio de Janeiro: Edições Graal, 1981.

RICARDO, D. (1817). The Principles of Political Economy and Taxation. Londres: J.M. Dents \& Sons Ltd., 1957. Tradução para o português: Princípios de Economia Política e Tributação. Coleção Os Economistas. São Paulo: Abril Cultural, 1982.

SERRANO, F.; FREITAS, F. O Supermultiplicador Sraffiano e o Papel da Demanda Efetiva nos Modelos de Crescimento. Mimeo, 2007.

SIMONSEN, M. H. Ensaios Analíticos, 2a edição. Rio de Janeiro: FGV, 1994.

SMITH, A. (1776). An Inquiry into the Nature and Causes of the Wealth of Nations, $5^{\mathrm{a}}$. edição. Londres: Methuen \& Co., Ltd., 1904. Tradução para o português: Uma Investigação sobre a Natureza e Causas da Riqueza das Nações. Coleção Os Economistas, $3^{a}$ edição. São Paulo: Nova Cultural, 1988.

THIRLWALL, A. P. The Balance of Payments Constraint as an Explanation of International Growth Rate Differences. Banca Nazionale Del Lavoro Quarterly Review, págs. 45-55, março, 1979.

THWEATT, W. O. A Diagrammatic Presentation of Adam Smith's Growth Model. In: Wood, J. C. (eds.). Adam Smith: Critical Assessments, vol. III. Londres: Routledge, 1994.

Recebido em 08.03.15

Aprovado em 14.05.15 